\title{
DEVELOPING AN EXPERIENTIAL LEARNING MODEL FOR STUDENTS OF ENGLISH FOR ACADEMIC PURPOSES TO USE IN THEIR FURTHER STUDIES - A REFLECTION
}

\author{
Vera Maria Nistor
}

\section{INTRODUCTION}

As part of my Master of Professional Practice research project, I developed a learning model for my students of English for Academic Purposes. The main motivation behind this idea was that during my teaching career I have always wanted to find ways to get my students to become more independent and to help them get better learning habits, but I never developed anything original and personalised for my students.

My project's research question was "could a learning model or process help students learn better both in English and in other subjects?" I developed an approximate experiential learning model that I thought would be suitable for my English students. However, I did not want to just give my students this model, but instead, I wanted to guide them to find what was right for them and to make any adjustments as they thought necessary. The plan was to work alongside my students in English class, to collaborate on the development of a learning model that would work for them. Eventually, I was going to follow up with them once they had progressed to their main degree courses, in order to see if they were still using it after finishing their English course.

\section{LITERATURE REVIEW}

To support my research on finding an experiential learning model for my English students, I looked at both literature from the field of English for Speakers of Other Languages (ESOL), which is inherently more inclined to be experiential due to its practical nature (Knutson, 2003), as well as more general literature on experiential learning cycles and their role in the field of education in general.

One of the most popular modern ESOL strategies and the strategy at the basis of my experiential learning model, is task-based learning (Willis, 1996). This theory is mainly based on the concept of 'learning by doing' and its normal structure is pre-task, task cycle and language focus. This means that the teacher introduces the topic so that students are familiar with it, then sets a communicative task which should ideally inspire the language focus that needs to be addressed (based on the teacher's monitoring), and then after the language focus is explicitly addressed with the students, the same task (or a similar one) is once again set. There are many supporters of this experiential theory, which seems to be a more efficient way to learn than the classic lecturing, as students can more clearly learn from their own mistakes and are offered a more "holistic experience" (Willis, 1996, p. 40).

A study by Macaro (2006) outlines some popular 'learner strategies' for learners of a second language. He refers to Oxford and Burry-Stock in showing that language learning seems to be more successful through "generally high strategy use" (Macaro, 2006, p. 320) and that motivation can also be affected positively by strategy use. This study focuses on specific ESOL strategies, such as strategies to learn new vocabulary, or to become a better speaker 
or writer, but metacognition is an idea that can be applied further to any similar practical subject. Archibald et al. believe that metacognitive learning strategies "are seen as the gateway to successful integration of language learners into mainstream classrooms" (2008). This further distances modern learning from traditional learning, in that it is no longer believed it is enough for students to just automatically learn all the information they receive in class without asking questions and without delving deeper into the reasons why this is important for their knowledge or life.

Probably one of the most well-known experiential learning depictions in modern education is Kolb's (1984) learning cycle of experiential learning (based on Lewin's experiential learning model). It consists of a concrete experience, followed by reflective observation and abstract conceptualisation, and finally active experimentation which puts everything into practice and extends the purpose of the experience into other contexts.

However, when it comes to learning from experience, the model that has inspired most other authors on this topic is Dewey's 'theory of experiential continuum' (1938). At its core, this theory shows that students learn from previous experiences, which then in turn inform present and future experiences: "the experiential continuum" based on the "category of continuity" (Dewey, 1938, p. 33). In his book Experience and Education, he emphasises the need for a purpose to each experience in order to enable an actual learning process in students through organised activities. He names the following as the formation of purpose in the context of learning through experience: observation of surrounding conditions, knowledge of what has happened in similar situations in the past (your experience or others'), and judgement which puts together what is observed and what is recalled to see what they signify.

'Reflective practice' (Moon, 2004) has also been a part of any ESOL class in order to accomplish the understanding of how language is being retained and improved. However, reflection is a useful tool in any subject, following any task. "It will usually involve the sorting out of bits of knowledge, ideas, feelings, awareness of how you are behaving and so on" (Moon, 2004, p. 187), this whole process of re-organising and clarifying your thoughts Moon refers to as "cognitive housekeeping" (2004, p. 188). Reflection is arguably one of the most important components of an experiential learning cycle, in that without reflection learning from experience would not be possible.

At the heart of all of these learner-centred methodologies lies the concept of 'facilitation', meaning the teacher acts more as a facilitator or 'guide' (Richards, 1998) than an actual 'teacher' in the classic sense of the word. Their main responsibility is to "create lessons that enhance communication and cooperation between learners" (Richards, 1998, p. 52), in order to increase their autonomy. Heim (2012) also negatively refers to the teacher as an 'expert', who represents a figure of absolute authority for the students, and somebody students might even fear, rather than feeling comfortable cooperating with. She points out that there is a crucial difference between "having expert knowledge" and "using that expert knowledge to dominate a group" (Heim, 20I2).

Going hand in hand with the idea that the teacher needs to take a step back and take on the role of facilitator for a class to become truly learner-centred, a higher degree of autonomy should also be encouraged in the students. This idea of student autonomy has been recently discussed in the context of a psychological theory called "selfdetermination theory" (Ryan \& Deci, 2017), which is closely linked to student motivation, and namely to the intrinsic motivation that students have and that involuntarily influences each one of their choices when it comes to how they learn. Another aspect linked to student autonomy is the idea of a teacher co-creating class materials, and even assessments together with the students. Rogers, Lyon and Tausch (2014) have written about "personcentred freedom" and supported the idea that each student should be more actively involved in the processes regarding their own learning. 


\section{RESEARCH METHODS}

Overall, I used a pragmatic research methodology, which is, as described by Patton (2002), an eclectic approach that uses multiple research methods. It is less traditional or restrictive, and relies on abductive reasoning in that it is believed different methods can all be used as long as they are appropriate for the analytical purposes. The reason why this particular qualitative methodology was the most suited for my project was the interactive nature of pragmatic research, as well as the flexibility in approaches (Patton, 2002).

The overarching research method I used for the entire project was action research (Lewin, 1946), which is made up of different cycles of planning something, trying out that activity, and then evaluating the results, in order to learn from this and inform subsequent trial cycles. The project consisted of a total of three cycles and at the end of each cycle the data was analysed and lessons were learned from it in order to inform the next cycle, of research. In Cycle I, I interviewed past English students, in order to gauge how responsive and prepared the students were to engage with an experiential learning model, as well as to rethink my approach in terms of how to present this model to them. In Cycles 2 and 3, I worked with and surveyed current students, in order to try and get them to develop this experiential learning model.

Due to the pragmatic nature of the research, a triangulation approach was used (Long, 2005; Patton, 2002) to increase the validity of the qualitative research. Long (2005) recommends using both multiple sources of data (in my case three different cycles working with three different groups of students) and multiple methods (in my case qualitative surveys, focus groups, as well as informal observations).

For the analysis of the data gathered from both the qualitative surveys (written responses to open-ended questions) and the focus groups (oral responses), thematic analysis seemed like the most suitable process; in other words, finding themes in large chunks of data and summarising them across participants (Patton, 2002).

Regarding ethics, all data was collected using ethical methods strictly following the ethics approval guidelines for this research project. My current students were always surveyed anonymously, and only former students were allowed to participate in focus groups.

\section{RESULTS}

\section{Cycle I}

Cycle I was a retrospective action, where I only worked with former English students. I conducted focus groups and an online survey with them in order to get a general idea of whether they had found anything particularly useful from what they had learned on their English course, and if they had used any of these skills or methods in their main degree courses as well. I wanted to see if the fact that they did this course based on ESOL strategies helped them learn better after they finished it, and if they took something practical away from this. This information was then going to be used to plan Cycles 2 and 3 with my current students.

The main finding from Cycle I was that students generally found the English course very useful and appreciated the practical nature of the course. They also remembered some particular skills that they learned and which proved very useful in their main degree courses as well, such as presentation skills and academic writing. From their answers, it was clear that students were only able to make some temporary connections between isolated tasks and activities on the course, but they could not articulate any of these learning strategies they were using and this impacted on the way they were applying them later. As a teacher, I understood that if people do not understand exactly why and how they are doing something, they will probably not get any quality lifelong learning habits out of it. 


\section{Cycle 2}

Following the lessons learned from Cycle I, in Cycle 2 I introduced my current group of students to different learning strategies from the very beginning of their English course. This initiative was also aided by the curriculum for our course and by our textbook, which had a focus on metacognition and learning strategies. Throughout the course, the students had many opportunities to reflect on how they were learning and to trial different methods themselves, to see if they were working for them. In Cycle 2, I tried to guide my students as much as possible to develop a model of learning themselves, after knowing better and more explicitly about these ESOL learning strategies. I was hoping that by the end of Cycle 2 they would be able to choose their preferred way of learning and create something similar to the approximate learning model I had developed.

In an analysis of their responses from the end-of-course survey, they showed awareness and interest in separate learning strategies, but were not able to connect them and develop a learning model. I asked myself why the outcome was not what I had expected and I realised it might have been because my students were not from the field of education. It seems that it was too difficult for them to see the big picture all by themselves and connect everything. Their knowledge only remained at isolated tasks, isolated activities, which they applied in their learning, but they could not develop something overarching that could be applied to all these tasks consistently, in every learning situation. As an advocate of student autonomy, I wanted to give them more independence, but they would have benefitted from more input and guidance from me.

\section{Cycle 3}

After reconsidering the whole approach, I devised a new plan for Cycle 3. I took the learning model I had developed for my students and simplified it for them. I started again by making them aware of different learning strategies, and then I elicited the learning model from them, trying to obtain a model as close as possible to mine. Even if the model had been initially developed by me, I wanted them to have the feeling that they were part of the development process. I elicited the different steps from them while we were trying out a class activity where this learning model was being applied. We eventually came up with a simplified version of the ESOL-based experiential learning model together (Figure I).

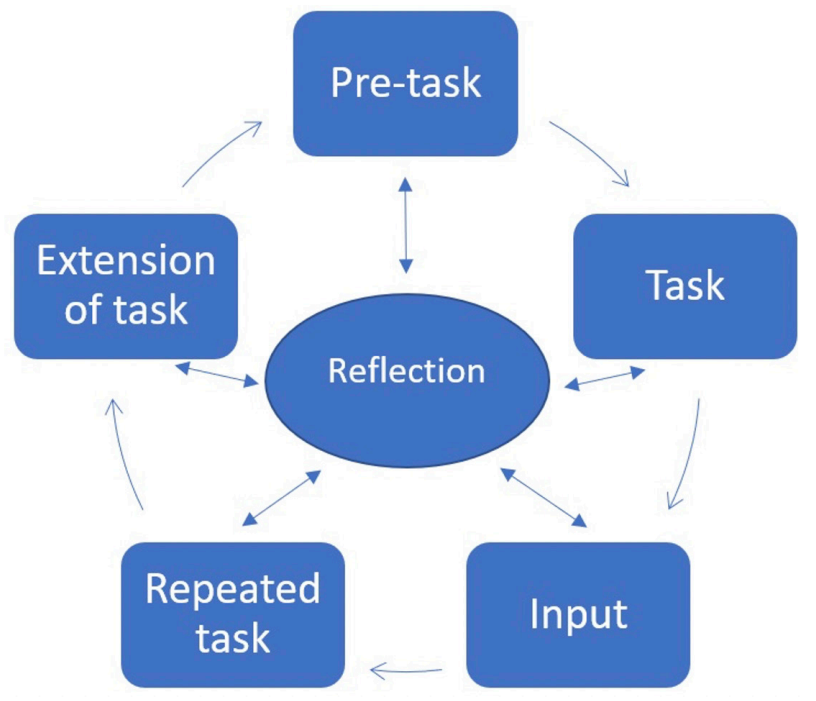

Figure I. Simplified experiential learning model 
The big difference in Cycle 3 was that they could see the model explicitly and follow it by applying it to different tasks, such as doing oral presentations and writing reports. Cycle 3 had a more complex structure, consisting of three different stages. Stage I was done with my current group of students and ended with an online anonymous survey. The responses from the students regarding the use of this model were very positive-they not only understood the model very well, but they used it successfully both in their English class, as well as in their daily life at work or in their free time. They also stated that they would definitely keep using it in future courses, as they found it very helpful. Stage 2 consisted of two focus groups with the same group of students, as I was no longer their teacher and another lecturer had taken over their English class for the second half of the course. Stage 3 consisted of one more focus group with the same group, once they had already been on their main degree course for a few weeks. Stages 2 and 3 were done in order to investigate the consistency with which they were still using the learning model and they confirmed that they were still actively using it, giving many interesting examples of activities where it was particularly useful for them. All throughout Cycle 3 I encouraged my students to try out the learning model and to personalise it to better suit their learning needs, but even after having started their main degree course they still did not wish to change it and were happy to use it the way it was.

\section{DISCUSSION}

Cycles I and 2 were very useful in terms of my action research, as they provided a lot of inspiration and I learned from past mistakes. This helped provide a better structure for Cycle 3, and gave the students the most of the opportunity to develop their present and future learning model.

In Cycle 3, the students were able to experience this learning model in three different stages, both with active teacher support, as well as more autonomously in Stages 2 and 3. They got to exercise student autonomy (Rogers et al., 2014; Ryan \& Deci, 2017) and understand that they can also learn without constant input from the teacher. They got more familiar with the idea of 'facilitation' (Heim, 2012; Knutson, 2003; Richards \& Rodgers, 1986) during the Stage I class time, as I tried to step away and let them make sense of these concepts and steps by themselves, even when we were in the actively taught phase of the learning model. In general, the learners got gradually more used to this "autonomy-supportive teaching" as opposed to the "controlling instructional behaviours" of more traditional teachers (Reeve, 2016, p. 131) and understood the benefits this type of flexible and inclusive class facilitation had for their motivation and learning. From the second focus group, it became more apparent that working in groups or teams during class time had helped them further engage with this learning model autonomously. They confirmed that following Cycle 3: Stage 2 of the autonomous practice with the learning model, they could use it autonomously and together with their peers during English class activities/tasks. They also believed that they could continue to use it in their future degree programmes the same way, even if their new teacher was not going to be using this model or actively reminding them of it.

In their responses to the qualitative surveys and focus groups, the students showed they not only understood the learning model, but also the importance of being aware of it and using it, or what Illeris refers to as the "understanding of learning", which is at the core of any learning model (2009). This further supports the idea that metacognition is highly appreciated by students and that it gives them an extra level of control over their own learning (Archibald et al., 2008; Macaro, 2006; Osterman, 1998). In their answers, they not only quoted examples of how we used the model in class, but were also able to give examples of how they used the model autonomously outside of class time, such as at work, in their pastimes, or even during their main degree course. This supports Dewey's belief and proves the increasing popularity of the active "inquiry-based approach to teaching and learning that is defined by agency, a questioning attitude, experiential engagement with resources and materials, discovery, integration, and an overall desire to continue learning" (Makaiau, Ragoonaden, Wang, \& Leng, 2018, p. 97). 


\section{CONCLUSION}

Even though it was an English language learning model at its core, the students noticed that this model was not limited to this subject and they understood the universality of the learning process. The students also realised by themselves that they were able to use this learning model independently, and that this would be very useful for them in a world where the focus in education is currently on self-development and self-study. They understood the need to develop their own learning habits, which do not need to be teacher-imposed or even teacher-led, and it seems that this experiential learning model has become one of their lifelong learning habits. Most importantly, this project showed that students are willing to delve deeper into metacognition and being in control of their own learning by exercising student autonomy and understanding these processes more explicitly.

My intention was to create a culture of learner-centred practice that any lecturer can use at tertiary level, irrespective of the subject they are teaching, based on the principles of 'ako' (to teach and to learn simultaneously) (Cameron, Berger, Lovett, \& Baker, 2007). This means considering students not just as students but rather as partners that are included in the decision-making process by facilitating experiences that are "context rich, relevant and appropriate, learner centred" (Edwards, 20I3). I would like to continue to give my students the opportunity and the tools to contribute to the development of a learning model that works for them and to support them in using it consistently, all along their learning journey. Ideally, this would inspire other tertiary educators to enable their own students to continually enhance their learning models in a student-centred environment.

Vera Maria Nistor is a Lecturer with the English Department at Otago Polytechnic Auckland International Campus, currently teaching Academic English to international students pursuing postgraduate studies in New Zealand. Her research interests include interdisciplinary research on experiential learning and learner-centred teaching practice, and their applicability across different academic subjects.

\section{REFERENCES}

Archibald, J., Bashutski, K., Guo, Y., Jaques, C., Johnson, C., McPherson, M., Roessingh, H., \& Shea, C. (2008). A Review of the Literature on English as a Second Language (ESL) Issues. Alberta, Canada: Alberta Education. Retrieved from: https://www.researchgate. net/publication/267701579_A_Review_of_the_Literature_on_English_as_a_Second_Language_ESL_Issues

Cameron, M., Berger, J. G., Lovett, S., \& Baker, R. (2007, April). Ako: being a teacher, being a learner, being part of a learning profession. Paper presented at the American Educational Research Association annual conference, Chicago. Retrieved from: https://www.nzcer.org.nz/system/files/I54l3.pdf

Dewey, J. (1938). Experience and Education. New York: Kappa Delta Pi.

Edwards, S. (20/3). Ako Wānanga: The Art, Science and Spiritual Endeavour of Teaching and Learning in a Wānanga: A Localised Approach. International Journal of Pedagogical Innovations, I(2), 69-73. Retrieved from: https://journal.uob.edu.bh

/handle//23456789/893

Heim, C. (2012). Tutorial facilitation in the humanities based on the tenets of Carl Rogers. The International Journal of Higher Education Research, 63(3), 289-298. https://doi.org/I0.1007/sI0734-0II-944I-z

Illeris, K. (2009). A comprehensive understanding of human learning. In K. Illeris (Ed.), Contemporary Theories of Learning (pp. 7-20). Oxon: Routledge.

Knutson, S. (2003). Experiential Learning in Second-Language Classrooms. TESL Canada Journal, 2(2), 52-64. https://doi. org/10.18806/tesl.v20i2.948

Kolb, D. A. (1984). Experiential Learning: Experience as The Source of Learning and Development. New Jersey: Prentice Hall.

Lewin, K.(1946). Action ResearchandMinorityProblems.JournalofSociallssues, 2(4), 34-46. https://doi.org/I0.1III/j. I540-4560.1946. tb02295.x 
Long, M. H. (2005). Second Language Needs Analysis. Cambridge, UK: Cambridge University Press.

Macaro, E. (2006). Strategies for Language Learning and for Language Use: Revising the Theoretical Framework. The Modern Language Journal, 90(3), 320-337. https://doi.org/I0.1111/j.1540-4781.2006.00425.x

Makaiau, A. S., Ragoonaden, K., Wang, J. C.-S., \& Leng, L. (2018). Developing an Inquiry Stance in Diverse Teacher Candidates: A Self-Study by Four Culturally, Ethnically, and Linguistically Diverse Teacher Educators. In J. Sharkey, \& M. M. Peercy (Eds.), Self-Study of Language and Literacy Teacher Education Practices (pp. 93- I14). Bingley, UK: Emerald Publishing Limited.

Moon, J. A. (2004). A Handbook of Reflective and Experiential Learning: Theory and Practice. Oxon: Routledge Falmer.

Osterman, K. F. (1998). Using Constructivism and Reflective Practice to Bridge the Theory/Practice Gap. The Annual Meeting of the American Educational Research Association, (pp. 9-20). San Diego.

Patton, M. Q. (2002). Qualitative Research \& Evaluation Methods. London: Sage Publications.

Reeve, J. (2016). Autonomy-Supportive Teaching: What It Is, How to Do It. In W. C. Liu, J. C. Wang, \& R. M. Ryan, Building Autonomous Learners: Perspectives from Research and Practice using Self-Determination Theory (pp. 129-152). Singapore: Springer.

Richards, J. C. (1998). Beyond Training. Cambridge, UK: Cambridge University Press.

Richards, J. C., \& Rodgers, T. S. (1986). Communicative Language Teaching. In J. C. Richards, \& T. S. Rodgers (Eds.), Approaches and Methods in Language Teaching (pp. 64-86). Cambridge, UK: Cambridge University Press.

Rogers, C. R., Lyon, H. C., \& Tausch, R. (2014). On Becoming an Effective Teacher: Person-centered teaching, psychology, philosophy and dialogues with Carl R. Rogers and Harold Lyon. Oxon: Routledge.

Ryan, R. M., \& Deci, E. L. (2017). Self-Determination Theory: Basic Psychological Needs in Motivation, Development, and Wellness. New York: Guilford Press.

Willis, J. (1996). A Framework for Task-Based Learning. Harlow, Essex: Addison Wesley Longman Limited. 